\title{
The Effect of Response Shift on Quality of Life among Cancer Patients: A Systematic Review
}

\author{
Li-Fen Chao', Jun-Yu Fan1, Fen-Fang Chung1, Hung-Bun Lam² \\ ${ }^{1}$ Department of Nursing, Chang Gung University of Science and Technology, Tao Yuan, Taiwan \\ ${ }^{2}$ Division of General Surgery, Department of Surgery, Mackay Memorial Hospital, Taipei, Taiwan \\ Email: Ifchao@mail.cgust.edu.tw
}

Received 28 September 2014; revised 30 October 2014; accepted 1 December 2014

Copyright (C) 2014 by authors and OALib.

This work is licensed under the Creative Commons Attribution International License (CC BY).

http://creativecommons.org/licenses/by/4.0/

(c) (i) Open Access

\section{Abstract}

Aims and Objectives: To scrutinize the evidence of response shift effect on published quality of life (QOL) studies investigating the patient-reported outcome to obtain accuracy data as evaluating clinical practice. Background: People may alter their internal standards, known as response shift, when they experience changes in their health status. This phenomenon can falsify patient-reported measures, and has gained increasing attention recently in explaining research paradoxical findings. Nevertheless a rigorous evidence-base about this effect on cancer patients QOL is lacking. Design: A systematic review was carried out under adhered to the guideline of the Quality of Reporting of Meta-Analyses. Methods: A comprehensive search was conducted on seven English and Chinese databases to identify and collect studies focus on cancer patients QOL. Methodological quality assessment was performed to assess the strength of evidence. Results: Using pre-determined keywords, 584 relevant titles were identified. Eventually 14 papers satisfied the inclusion criteria and entered the quality assessment stage. All the articles were written in English and published between 1996 and 2013. A majority of the studies used the then-test method, which is also known as the retrospective pretest-posttest design method. The weighted mean effect size (WMES) was $0.47(95 \% \mathrm{CI} 0.31$ to 0.63$)$. Using data from the six studies for assessing then-test/pre-test comparison on the outcome measure fatigue, the WMES was $-0.21(95 \% \mathrm{CI}-0.32$ to -0.10$)$. Conclusion: The alternation of self-internal standard occurs when cancer patients evaluated their QOL over a period of time. Relevance to clinical practice: This review emphasizes the need for a more sensitive approach to inspect the clinical impact of response shift by measuring changes in QOL. Patients' adaptation to the disease can then be more precisely acquired.

\section{Keywords}

Quality of Life, Evidence-Based, Response Shift, Then-Test, Cancer Patients

Subject Areas: Nursing, Oncology, Psychology

How to cite this paper: Chao, L.-F., Fan, J.-Y., Chung, F.-F. and Lam, H.-B. (2014) The Effect of Response Shift on Quality of Life among Cancer Patients: A Systematic Review. Open Access Library Journal, 1: e1099.

http://dx.doi.org/10.4236/oalib.1101099 


\section{Introduction}

Assessment of health related quality of life (HRQOL), a form of patient reported outcomes (PROs), is based on the patient-centered approach to the consequences of a disease or management results [1]-[4]. PROs have represented a major indicator on the appraisal of health care and services, particularly in cancer studies [5] [6]. Patients diagnosed with cancer are often perceived to be encountering a condition that is incurable; and treatment services are expected not only to preserve lives, but also to influence the overall wellbeing. The maintenance or improvement in HRQOL is likely to be considered a proper outcome [4]. The quantity of research investigating the HRQOL parameter has increased substantially; moreover, the Food and Drug Administration in the US has recommended that patient perceptions of HRQOL ought to be valued and appraised in all clinical trials relating to cancer research [7]-[9].

Basically, there are two assumptions in a longitudinal study using self-report measures. First, people hold an internalized standard for judging their present level regarding the subject of the investigation. Second, this internalized standard remains stable over time. However, it has been claimed that people may alter their internal standards of measurement, a response shift (RS) bias attribute, towards the perception of HRQOL when they accommodate to illness [10]. In clinical trials, the differences in HRQL across treatment arms may be influenced when RS affects the treatment groups differently [11]. Since this is a relatively new concept from a methodological viewpoint, it remains unclear to what extent RS occurs in different settings, although research in the area is emerging.

Response shift refers to changes which occurred in a person's self-evaluation of a target construct. Three types of RS have been noted; they are changes in one's internal standards (recalibration), values (reprioritization), and conceptualization (redefinition) of the construct within the domain of HRQOL [12] [13]. This concept is a psychological process that permits individuals to keep an acceptable QOL in the face of worsening health status. That is, as people become ill, they alter their prospects through recalibration, prioritizing life domains differently or changing their definition of what is major in order to adapt to their profound change.

\section{Aims}

In general, measures of QOL are patient-reported outcomes that can be distorted by the phenomenon of RS. Thus, this concept has gained increasing attention recently in explaining paradoxical and counter-intuitive findings [14]-[16]. Assessing such variation might provide researchers and clinicians with guidance on how to handle the range of shift they might encounter. To date, no one has scrutinized how the phenomenon affects the estimation of QOL in cancer patients. We therefore conducted this comprehensive review to analyze studies that measured or described the effect of RS on cancer patients' QOL, and to examine the strength of the effect when it occurred. We are aware of earlier reviews [17] [18], which did not examine the effect of RS variation on QOL outcomes in cancer patients. There was also a need to update this information to facilitate and stimulate further research in this area.

\section{Methods}

The conduct and presentation of this systematic review adhered to the guideline of the Quality of Reporting of Meta-Analyses (QUOROM) [19].

\subsection{Search and Screening Strategy}

Two independent reviewers conducted a systematic literature search of the following bibliographical databases: PubMed, Cochrane library, EMBASE, the Cumulative Index to Nursing and Allied Health, PsycINFO, and three Chinese databases: CNKI, CEPS, and WanFang. All databases were retrieved from their inception until August 2012. Search terms consisted of three components: 1) Clinical conditions: Cancer disorder (and variants); 2) Outcome measures: Quality of life, subjective well-being (and variants); and 3) Target event: The issue of response shift. Medical terms for "cancer" (e.g., neoplasm, carcinoma, tumour) were combined separately with at least one of the following words related to "response shift" phenomena, e.g., "response shift", "framing", "frame of reference", "change" and "shift". In addition, hand searching was conducted and references quoted in all retrieved articles reviewed for any additional study. No language restriction was applied. 


\subsection{Inclusion and Exclusion Criteria}

A study was considered eligible if it satisfied all the following criteria: 1) Study design: Employing a longitudinal and quantitative design to explicitly assess the happening of response shift of QOL variables; 2) Participants: Cancer survivors at any stage and undergoing any type of therapy; 3) Available articles: Full-text published papers. Reports that were available only in abstract form were excluded.

\subsection{Methodological Quality Assessment}

All studies included were assessed independently by two experienced reviewers using standardized criteria (Table 1). Our internal training ensured that we consistently applied criteria across the studies reviewed. Items included in the assessment scale were modified from two previous reviews [18] [20]. For each item in the scale a score "1" was given when the criterion was satisfied; but "0" when the salient information was absent or unclear. Agreement between the two raters was calculated using agreement rate (AR) and Cohen's kappa [21]; discrepancies were resolved by discussion with a third reviewer. The sum of scores of all relevant items was treated as the internal validity index. Similar to a previous review [22], we converted the total score of each study into a percentile as a standardized score. A high quality study was defined as having a standardized score of $50 \%$ or higher.

\subsection{Data Extraction and Synthesis}

The following information from each paper was recorded: the first author, year of publication, population parameters, design, measure(s), indicators for RS, main results, and the effect size (ES). For studies that assessed RS by comparing the baseline score versus the retrospective score, i.e. then-test, we calculated the ES of individual studies by the mean difference between the then-test and pretest on baseline standard deviation. Furthermore,

Table 1. Results of the methodological quality score on the studies included.

\begin{tabular}{|c|c|c|c|c|c|c|c|c|c|c|c|}
\hline \multirow{2}{*}{ Study } & \multicolumn{11}{|c|}{ Criteria* } \\
\hline & 1 & 2 & 3 & 4 & 5 & 6 & 7 & 8 & 9 & 10 & Total/10 \\
\hline Spranger, 1996 [46] & 0 & 0 & 0 & 0 & 0 & 0 & 1 & 0 & 1 & 0 & 2 \\
\hline Spranger, 1999 [47] & 0 & 1 & 1 & 1 & 0 & 0 & 1 & 1 & 1 & 1 & 7 \\
\hline Schwartz, 1999 [48] & 0 & 1 & 0 & 1 & 1 & 1 & 1 & 1 & 1 & 1 & 8 \\
\hline Visser, 2000 [49] & 0 & 1 & 1 & 1 & 0 & 0 & 0 & 1 & 1 & 1 & 6 \\
\hline Jansen, 2000 [50] & 0 & 1 & 1 & 1 & 0 & 0 & 1 & 1 & 1 & 1 & 7 \\
\hline Bernhard, 2001 [51] & 1 & 1 & 1 & 1 & 0 & 1 & 1 & 1 & 1 & 1 & 9 \\
\hline Visser, 2005 [52] & 0 & 1 & 1 & 1 & 1 & 0 & 1 & 1 & 1 & 1 & 8 \\
\hline Rees, 2005 [53] & 0 & 1 & 1 & 1 & 0 & 1 & 1 & 1 & 1 & 1 & 8 \\
\hline Korfage, 2007 [54] & 0 & 1 & 1 & 1 & 0 & 0 & 1 & 1 & 1 & 1 & 7 \\
\hline Andrykowski, 2009 [55] & 0 & 1 & 0 & 1 & 0 & 0 & 1 & 1 & 1 & 1 & 6 \\
\hline Lepore, 2000 [56] & 0 & 0 & 0 & 0 & 0 & 0 & 1 & 1 & 1 & 1 & 4 \\
\hline Hagedoorn, 2002 [57] & 0 & 1 & 1 & 1 & 0 & 1 & 1 & 1 & 1 & 1 & 8 \\
\hline Oort, 2005 [58] & 0 & 1 & 1 & 1 & 0 & 0 & 1 & 1 & 1 & 1 & 7 \\
\hline Sharpe, 2005 [59] & 0 & 1 & 1 & 1 & 0 & 0 & 1 & 1 & 1 & 1 & 7 \\
\hline No. of studies meeting criterion & 1 & 12 & 10 & 12 & 2 & 4 & 13 & 13 & 14 & 13 & - \\
\hline
\end{tabular}

If the item met the list of criteria, it was scored " 1 ”; did not meet the criteria or the description was not clear, it was scored "0”" * 1 ) All patients or random sampling; 2) Description of inclusion criteria; 3) Description of exclusion criteria; 4) Description of drop-outs; 5) Reported power analysis; 6) Healthy or reference samples comparison; 7) Well-reported psychometric evaluation or standardized, validated instruments; 8) Description of the study population main features; 9) Adequate statistical tests; 10) Adequately reported statistical tests. 
studies were considered "comparable" if they had used similar outcome measures. To maximize the comparability of ES estimates across studies, and to lessen the bias of multiple comparisons, QOL information extracted for ES estimation from each longitudinal study included only the baseline measure and the measure at the first time point after 2 months, even if the study used the "then-test" more than twice. Once two or more comparable studies are identified, data were pooled into a meta-analysis according to the sample size of each study to determine the effect of the response shift occurrence. Double data entry was used to minimize the risk of data entry errors.

\subsection{Statistical Analysis}

The Effect Size Determination Program [23] was used to calculate the ES of each study. When no exact information about the mean and/or standard deviation was provided, we converted the ES from the $p$ value. The software program Comprehensive Meta Analysis (V2) [24] was employed to calculate the overall effect size; "forest plot" was used to assess possible publication bias [25]. Statistical heterogeneity was detected with the Cochrane's Q-statistic. We assessed the extent of the differences between the two endpoints measures using Cohen's classification of effect size and interpreted the standardized differences (d) of 0.2, 0.5, and 0.8 as "small", "medium”, and "large" effect [26].

\section{Results}

\subsection{Literature Search}

A total of 584 references were identified through the database and bibliographies search. After deleting repetitious and irrelevant studies by examining the titles and abstracts, 38 possible relevant studies remained. After scrutinizing these studies by applying the selection criteria, 24 articles that did not meet the inclusion criteria were excluded: not original researches [27]-[29] or duplication [30], only using qualitative assessment [31]-[33], lack of separated outcome in response shift of QOL [15] [31]-[39] or not applying to oncological patients [39][45]. In addition, previous researches indicated that fatigue that often appears in cancer patients is especially prone to response shift, and it is covered by the SF-36. Thus, the present study included papers which only explored fatigue domain for response shift. Eventually 14 articles were considered eligible and selected to enter methodological quality assessment [46]-[59]. Figure 1 displays the detailed selection process.

\subsection{Methodological Quality Assessment}

Inter-rater reliability in methodological quality assessment was excellent [21] (Cohen’s kappa =0.89; AR =

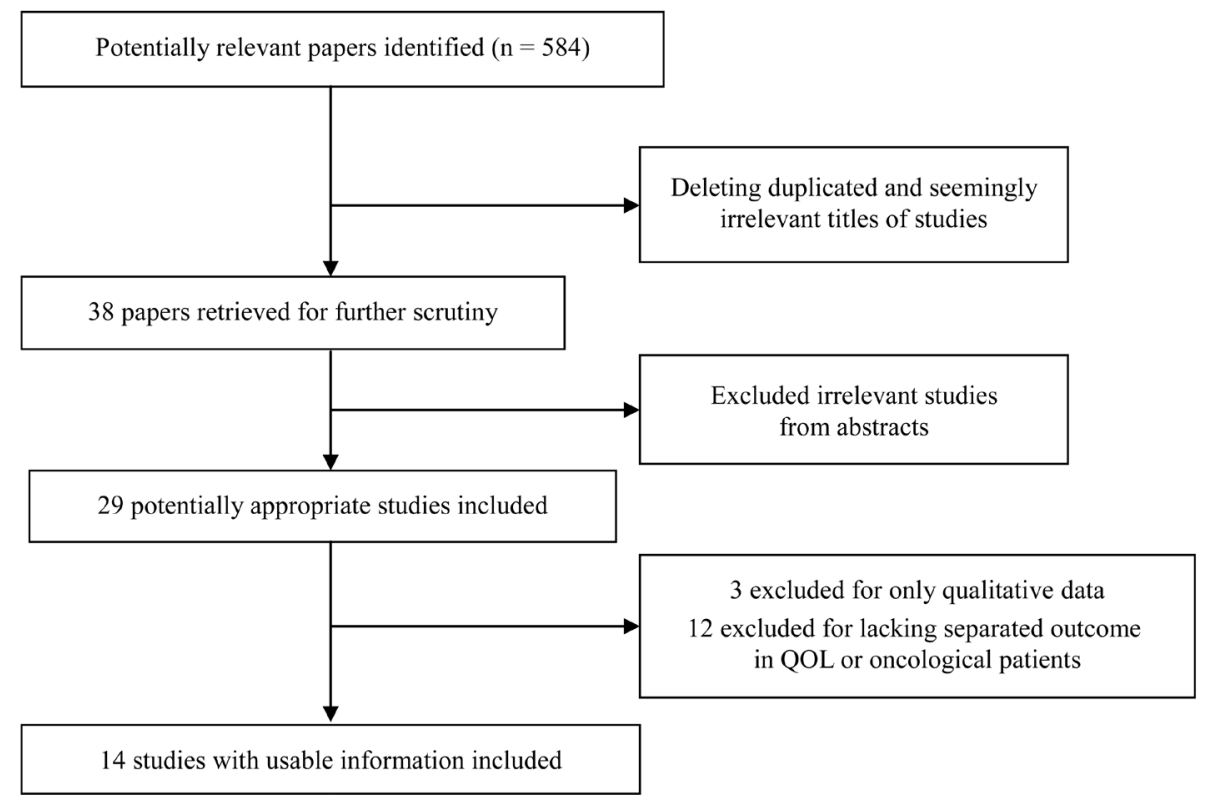

Figure 1. Flow chart for process of this systematic review. 
0.93). In case of disagreement between the two raters, consensus was achieved by discussion. Most studies (85.7\%) obtained more than 6 points, including one with 9 points and five with 8 points (Table 1). Only two studies [48] [52] had provided sample size justification. Four studies [48] [51] [53] [57] including a randomized design [51] had healthy or control groups to make a comparison. Of all the studies included, only one was deemed not good enough because it lacked descriptions on population selection and study design.

\subsection{Study Characteristics}

These 14 articles were published in journals or books between 1996 and 2009, and were conducted mainly in Netherlands $(8 / 14 ; 57.1 \%)$ and the United States $(4 / 14 ; 28.6 \%)$. There were a total of 1438 participants. The age of the subjects ranged from 18 to 89 years. Sample sizes ranged from small to moderately large $(n=23$ to $n=$ 240). Eight studies (57\%) included over 100 participants. The articles were heterogeneous in terms of cancer groups; six studies were associated with one cancer group only, including three prostate cancer [53] [54] [56], 2 breast cancer [50] [55] and one colon cancer [51].

The studies used various modes of estimation for response shift. More than 80\% (12/14, 85.7\%) [46]-[56] [58] investigated recalibration RS, three studies (21.4\%) [52] [58] [59] examined additionally reconceptualization and reprioritization. The only one randomized study [51] found no difference between groups in RS assessment; hence all participants' data in that study was integrated to estimate the change of internal standard. When multiple reports of the same research [52] [58] [59] were available, relevant information was extracted to analyse separately. In addition, where the RS types analyzed were different, two reports [52] [58] which may be based on a single sample of subjects were considered as two separate studies.

The characteristics of all the studies are summarized in Table 2. These response shift studies addressed domains generally considered important in QOL research.

\subsection{Instruments Used}

There were 10 different scales used among the trials. A majority used the Medical Outcomes Study Short-Form Health Survey (SF-36 or SF-12) (6/10; 60\%) [48] [50] [52] [54] [56] [58], the European Organization for Research and Treatment of Cancer Core Quality of Life questionnaire (EORTC QOLQ-C30) (40\%) [46] [47] [54] [57], and Multidimensional Fatigue Inventory (MFI) [46] [47] [52] [58]) (Table 2). All instruments used in these studies, except one [49], had well validated psychometric properties.

\subsection{The Estimation of Response Shift}

Three major modes were used to explore response shift effect. 12 articles $(85.7 \%)(\mathrm{N}=1073)$ addressed the effect of recalibration (internal standard change) on QOL assessment [46]-[56] [58], and a few projects used a statistical method (structural equation modeling, SEM) for reconceptualization and reprioritization assessment. Nearby half of the studies addressing "then-test" were available for meta-analysis to examine the strength of the effect once it occurred. The three methods carried out are explained below.

\subsection{Recalibration Response Shift}

As previously mentioned, in the 12 articles that explored the effect of recalibration, the "then-test" was most commonly used to estimate the recalibration, except two studies [56] [58]. In conventional study design, alterations in PROs are calculated by taking the difference between the beginning and the first available follow-up time point, which typically are the pretest and posttest. The then-test is a retrospective reassessment of the pretest (RPT) [40] at the time same as the posttest. Both the then-test and posttest are done at a specific moment and the same internal standard of measurement was selected. The distinction between the then-test/pretest comparison is taken as the effect of response-shift.

Nine projects had a follow-up period over 2 months. The other two [46] [49] reported that their period of retrospective appraisal was before and after radiation treatment of prostate cancer; which means it was at least 3 months. The shortest follow-up time was one week after the participants received a psychosocial intervention [48]. Global QOL (GQL) and Fatigue (FT) were the two indicators most commonly used for assessing RS, being used in five [48] [50] [51] [53] [54] and six [46] [47] [49] [50] [52] [55] studies, respectively. Other indicators such as Pain [52] or Vitality [54] were used in only one study; thus no comparable data was available for ES calculation. 
Table 2. Characteristic of studies included.

\begin{tabular}{|c|c|c|c|c|c|c|c|}
\hline Study & Cancer population & $\begin{array}{l}\text { Quality } \\
\text { score }\end{array}$ & $\begin{array}{c}\text { The method/pattern } \\
\text { of examining RS }\end{array}$ & Instruments & $\begin{array}{l}\text { Domains of } \\
\text { QOL assessed } \\
\text { (subscale) }\end{array}$ & $\begin{array}{l}\text { Timing of } \\
\text { assessment } \\
\text { duration }\end{array}$ & $\begin{array}{l}\text { The effect of } \\
\text { RS/Cohen's ES }\end{array}$ \\
\hline $\begin{array}{l}\text { Spranger, } 1996 \\
\text { /Netherlands } \\
\text { [46] }\end{array}$ & $\begin{array}{l}\text { Prostate or Breast } \\
\text { cancer; } \mathrm{N}=26 \text { under } \\
\text { R/T; age: N/R }\end{array}$ & 2 & Thentest/recalibration & $\begin{array}{l}\text { EORTC } \\
\text { QLQ-30 }\end{array}$ & $\begin{array}{l}\text { PWB, physical } \\
\text { role, emotional } \\
\text { and social } \\
\text { function, GQL, }\end{array}$ & $\begin{array}{l}\text { Pre- and } \\
\text { post-R/T }\end{array}$ & $\begin{array}{l}\text { Sig. on FT/-0.809 } \\
\text { (underestimate) }\end{array}$ \\
\hline $\begin{array}{l}\text { Spranger, } 1999 \\
\text { /Netherlands } \\
\text { [47] }\end{array}$ & $\begin{array}{l}\text { Heterogeneous } \\
\text { cancer site; } \mathrm{N}=105 \\
\text { under } \mathrm{R} / \mathrm{T} ; \\
\text { age: } 28 \text { - } 89\end{array}$ & 7 & Thentest/recalibration & $\begin{array}{l}\text { EORTC } \\
\text { QLQ-30 } \\
\text { MFI }\end{array}$ & FT & $\begin{array}{l}\text { Pre- and } \\
\text { post-R/T } \\
\text { (4 - } 7 \text { weeks) }\end{array}$ & in $\mathrm{FT} /-0.24$ \\
\hline $\begin{array}{l}\text { Schwartz, } 1999 \\
\text { /USA [48] }\end{array}$ & $\begin{array}{l}\text { Heterogeneous; } \\
9 \mathrm{~N}=23 \text { under PI, } \\
\text { drop-out: 1; age: } \\
22 \text { - } 29 \text { (mean: 22) }\end{array}$ & 8 & $\begin{array}{l}\text { Thentest/recalibration } \\
\text { Covariance } \\
\text { health compared } \\
\text { (only in baseline) }\end{array}$ & $\begin{array}{l}\text { SF-12; } \\
\text { RHS }\end{array}$ & $\begin{array}{l}\text { PWB, MH, } \\
\text { PswB, GQL }\end{array}$ & $\begin{array}{l}\text { 1) one week } \\
\text { 2) } 3 \text { mo later }\end{array}$ & $\begin{array}{l}\text { in } \mathrm{GQL} \\
\text { 1) } \mathrm{NS} /-0.1 \\
\text { 2) } p<0.05 / 0.6 \\
\text { Conventional change: ns } \\
\text { True change: } p<0.01\end{array}$ \\
\hline $\begin{array}{l}\text { Visser, } 2000 \\
\text { /Netherlands } \\
\text { [49] }\end{array}$ & $\begin{array}{l}\text { Heterogeneous; } \mathrm{N}= \\
216 \text { under combined } \\
\text { treatment, drop-out: } \\
\text { 17; mean age: } 64\end{array}$ & 6 & Thentest/recalibration & $\begin{array}{l}\text { Fatigue } \\
\text { NRS }\end{array}$ & FT & $\begin{array}{l}\text { Pre- and } \\
\text { post-R/T }\end{array}$ & $\begin{array}{l}\text { In FT/ }-0.127 \\
\text { Conventional change: ns } \\
\text { True change: } p<0.01\end{array}$ \\
\hline $\begin{array}{l}\text { Jansen, } 2000 \\
\text { /Netherlands } \\
{[50]}\end{array}$ & $\begin{array}{l}\text { Breast; } \mathrm{N}=46 \text { under } \\
\text { R/T; mean age: } 59\end{array}$ & 7 & Thentest/recalibration & $\begin{array}{l}\text { SF-36; } \\
\text { RSCL }\end{array}$ & $\begin{array}{l}\text { FT, PWB, } \\
\text { PswB, GQL }\end{array}$ & 6 - 7 weeks & $\begin{array}{l}\text { in GQL/ } 0.6 \text {; } \\
\text { in FT/-0.128 } \\
\text { Conventional change: } \\
p=0.04 \\
\text { True change: } p<0.01\end{array}$ \\
\hline $\begin{array}{l}\text { Bernhard, } 2001 \\
\text { /Switzerland } \\
\text { [51] }\end{array}$ & $\begin{array}{l}\text { Colon; } \mathrm{N}=134 \\
\text { under cancer surgery } \\
\text { with adjuvant } \\
\text { treatment }\end{array}$ & 9 & $\begin{array}{l}\text { Thentest/recalibration } \\
\text { Randomized to } 3 \text { arms }\end{array}$ & LASA & $\begin{array}{l}\text { SHE; PWB; } \\
\text { GQL }\end{array}$ & $\begin{array}{l}2 \text { mo } \\
\text { post-adjuvant } \\
\text { tx }\end{array}$ & $\begin{array}{l}\text { In GQL/ } 0.298 \\
\text { Conventional change: NS } \\
\text { True change: } p=0.001\end{array}$ \\
\hline $\begin{array}{l}\text { Visser, } 2005 \\
\text { /Netherlands } \\
{[52]}\end{array}$ & $\begin{array}{l}\text { Heterogeneous; } \mathrm{N}= \\
170 \text { under cancer } \\
\text { surgery, mean age: } \\
57.7\end{array}$ & 8 & $\begin{array}{l}\text { Thentest/recalibration } \\
\text { SEM/ } \\
\text { reconceptualization }\end{array}$ & $\begin{array}{l}\text { SF-36 } \\
\text { MFI }\end{array}$ & $\begin{array}{l}\mathrm{PF}, \mathrm{RP}, \mathrm{BP}, \\
\mathrm{GH}, \mathrm{VT}, \mathrm{SF}, \\
\mathrm{RE}, \mathrm{MH}, \mathrm{FT}\end{array}$ & $\begin{array}{l}3 \text { mo } \\
\text { post-surgery }\end{array}$ & $\begin{array}{l}\text { In FT/-0.05 (recalibration) } \\
\text { In RP/-0.26; BP/-0.29; } \\
\mathrm{GH} /-0.15 \\
\text { (reconceptualiztion) } \\
\text { Other/ns }\end{array}$ \\
\hline $\begin{array}{l}\text { Rees, } 2005 \\
\text { /UK [53] }\end{array}$ & $\begin{array}{l}\text { Prostate; } \mathrm{N}=55 \\
\text { under cancer surgery, } \\
\text { mean age: } 72.9\end{array}$ & 8 & $\begin{array}{l}\text { Thentest/recalibration } \\
\text { partner compared }\end{array}$ & $\begin{array}{l}\text { PPP } \\
\text { GCD }\end{array}$ & $\begin{array}{l}\text { SF, } \\
\text { treat-worried, } \\
\text { BP, PF, Sexual } \\
\text { function }\end{array}$ & $\begin{array}{l}3 \text { mo \& } 6 \text { mo } \\
\text { post-diagnosis }\end{array}$ & $\begin{array}{l}\text { In GQL/ } 0.828 \\
\text { In BP \& sexual function } \\
\text { of patient group: } \\
\text { RS occurred }\end{array}$ \\
\hline $\begin{array}{l}\text { Korfage, } 2007 \\
\text { /Netherlands } \\
\text { [54] }\end{array}$ & $\begin{array}{l}\text { Prostate; } \mathrm{N}=52 \\
\text { under vary treatment } \\
\text { mean age: } 67.3\end{array}$ & 7 & Thentest/recalibration & $\begin{array}{l}\text { SF-36, } \\
\text { EuroQol }\end{array}$ & $\begin{array}{l}\text { MH, VT, } \\
\text { Global health }\end{array}$ & $\begin{array}{l}1 \mathrm{mo} \& 7 \mathrm{mo} \\
\text { post-diagnosis }\end{array}$ & $\begin{array}{l}1 \mathrm{mo} \text { in } \mathrm{VT} / 0.28 \\
7 \mathrm{mo} \text { in } \mathrm{GQL} / 0.43 ; \\
\text { in vitality/0.26 }\end{array}$ \\
\hline $\begin{array}{l}\text { Andrykowski, } \\
\text { 2009/USA [55] }\end{array}$ & $\begin{array}{l}\text { Breast; } \mathrm{N}=102 \text { with } \\
\text { adjuvant treatment, } \\
\text { mean age: } 54.7\end{array}$ & 6 & $\begin{array}{l}\text { Thentest/ } \\
\text { recalibration }\end{array}$ & FSI & FT & $\begin{array}{l}2 \text { mo \& } 4 \text { mo } \\
\text { post-treatment }\end{array}$ & $0.33-0.5$ \\
\hline $\begin{array}{l}\text { Lepore, } 2000 \\
\text { /USA [56] }\end{array}$ & $\begin{array}{l}\text { Cancer: Prostate; } \\
166 \text { pts under } \\
\text { vary treatment }\end{array}$ & 4 & $\begin{array}{l}\text { Buffer model } \\
\text { regression/recalibration } \\
\text { Nominate priorities/ } \\
\text { reprioritization }\end{array}$ & $\begin{array}{l}\text { SF-12 } \\
\text { PCI }\end{array}$ & $\begin{array}{l}\text { MCS: emotional } \\
\text { and social } \\
\text { function; RF; } \\
\text { VT; PWB }\end{array}$ & 10 weeks & $\begin{array}{l}\text { N/A, modeling } \\
\text { approved RS affected } \\
\text { QL assessing }\end{array}$ \\
\hline $\begin{array}{l}\text { Hagedoorn, } \\
\text { 2002/ } \\
\text { Netherlands } \\
{[57]}\end{array}$ & $\begin{array}{l}\text { Cancer: } \\
\text { Heterogeneous; } \\
240 \text { pts in } \mathrm{C} / \mathrm{T} \text {, } \\
\text { mean age: } 50.5\end{array}$ & 8 & $\begin{array}{l}\text { Buffer model } \\
\text { Significant others, } \\
\text { research assistants } \\
\text { compared }\end{array}$ & $\begin{array}{l}\text { EORTC } \\
\text { QLQ-C30 }\end{array}$ & $\begin{array}{l}\text { PF, emotion, } \\
\text { GQL }\end{array}$ & $3 \mathrm{mo}$ & $\begin{array}{l}\text { In PF: patients felt } \\
\text { worse compared to } \\
\text { others, occurred RS }\end{array}$ \\
\hline
\end{tabular}




\section{Continued}

\begin{tabular}{|c|c|c|c|c|c|c|c|}
\hline $\begin{array}{l}\text { Oort, } 2005 \\
\text { /Netherlands } \\
{[58]}\end{array}$ & $\begin{array}{l}\text { Cancer: } \\
\text { Heterogeneous; } \\
170 \text { pts in I/S }\end{array}$ & 7 & $\begin{array}{l}\text { SEM/recalibration, } \\
\text { reprioritization } \\
\text { reconceptualization }\end{array}$ & $\begin{array}{l}\text { SF-36 } \\
\text { MFI }\end{array}$ & $\begin{array}{l}\text { PF, RF, BP, } \\
\text { GH, VT, SF, } \\
\text { RE, MH, FT }\end{array}$ & $\begin{array}{l}3 \text { mo } \\
\text { post-surgery }\end{array}$ & $\begin{array}{l}\text { In RP/0.27, BP/0.30 } \\
\text { (recalibration) SF/-0.11 } \\
\text { (reprioritization) GH/0.14 } \\
\text { (reconceptualiztion) }\end{array}$ \\
\hline $\begin{array}{l}\text { Sharpe, } 2005 \\
\text { /Australia [59] }\end{array}$ & $\begin{array}{l}\text { Cancer: } \\
\text { Heterogeneous; } 38 \\
\text { pts in metastasis } \\
\text { stage, mean age: } 56\end{array}$ & 7 & $\begin{array}{l}\text { Nominate priorities/ } \\
\text { individualized method, } \\
\text { reprioritization, } \\
\text { reconceptualization }\end{array}$ & $\begin{array}{l}\text { SEIoL-DW; } \\
\text { FACT-G }\end{array}$ & $\begin{array}{l}\text { Nominating } \\
\text { different life } \\
\text { domains }\end{array}$ & $\begin{array}{l}3 \text { mo \& } 6 \text { mo } \\
\text { post-diagnosis }\end{array}$ & Non-significance \\
\hline
\end{tabular}

I/S invasive surgery; PI: psychosocial interventions; SF-12 or SF-36: medical outcomes study short-form health survey; SEIQoL-DW: schedule for the evaluation of individual quality of life-direct weighting; EORTC; QLQ-30: European Organization for Research and Treatment of Cancer Core quality of Life questionnaire; FACT-G: functional assessment of cancer therapy-general; RHS: Ryff happiness scale; PPP: prostate cancer patient and partner questionnaire; MFI: multidimensional fatigue inventory; FSI: fatigue symptom inventory; RSCL: rotterdam symptom checklist; PCI: prostate cancer index; MCS: mental component summary; NRS: numerical rating scale; SHE: subjective health estimation; PWB: physical well-being; GQL: global quality of life; pF: physical functioning; RP: role-physical; BP: bodily pain; GH: general health; VT: vitality; SF: social functioning; RE: role emotional; MH: mental health; FT: fatigue (as measured with MFI). "Effect sizes are calculated according to the formula M (difference score)/SD (difference score), the size values of 0.2, 0.5, and 0.8 are considered "small”, "medium”, and "large" (Cohen, 1988); No provide enough data origin for ES, underestimated ES by $p=0.05$; NA is not applicable; ns indicates non-significance.

Overall the results varied by the amount and domain tested (Table 2); the effect size (Cohen's $d$ ) ranged from 0.05 to 0.828 . One study [48] reported non-significant effect over a short period, but a moderate effect size $(d=$ 0.6 ) was observed on a 3-month follow-up. Judging the effect size on RS indicator, seven studies demonstrated the existence of RS $(d>0.2)$, with large effect observed in two studies $(d>0.8)$ [46] [53]. On the other hand, three studies [49]-[51] found no significant [49] [51] or only very small $(p=0.04)$ [50] differences between original comparisons, i.e. conventional change. When considering the response shift bias, the disparity (true change) consequence appeared to be noteworthy.

Furthermore, using Hedges' fixed effect model [60] we computed the weighted mean effect size (WMES) between then-test/pre-test comparison on the domains GQL and FT assessed across studies. As shown in Figure 2 and Figure 3 and Table 3, using data from five studies on GQL, the WMES was calculated to be 0.47 (95\% CI 0.31 to 0.63$)$, indicating a moderate significant between group difference in the level of scoring. The homogeneity test statistic was not significant $\left(Q_{t}=5.499, d f=4, p=0.24\right)$ indicating that the WMES was a meaningful summary measure [23]. Similar calculation procedures were employed on the six articles on the indicator of FT. The WMES was calculated to be -0.21 (95\% CI -0.32 to -0.095$)$, indicating a mildly significant difference between groups in the level of scoring. Again, the test statistic of homogeneity was not significant $\left(Q_{t}=10.858\right.$, $d f=5, p=0.054)$.

\subsection{Reprioritization and Reconceptualization Response Shifts}

Of the 14 articles included, three high quality studies [52] [58] [59] explored the reconceptualization and reprioritization response shifts. The results were quite similar. They found the RS was small, if any. Visser et al. (2005) [52] used the structural equation modeling (SEM) to identify reconceptualization of subjects undergoing surgery by evaluating changes in factor structure and loading over time. Eventually, small effects were obtained only on three domains of SF-36 $(d=-0.26 ;-0.29$, and -0.15 for Role Function, Bodily Pain and General Health, respectively) (Table 2). There were no significant findings on other domains reported in this study with a relatively large sample size $(n=170)$.

Sharpe (2005) [59] also reported no significant RS occurred within the subjects' expression on semi-structured individualized measures, the Schedule for Evaluation of Individual Quality of Life-Direct Weighting (SEIQOL-DW). This instrument was developed to assess the quality of life of patients from the individual's perspective. Respondents were first asked to nominate and describe the 5 areas of their lives that they consider to be most important for their QOL [61]. They were then asked to rate their current level of satisfaction/functioning in each area on a scale between worst possible and best possible $(0-100)$. A single index can be calculated by multiplying the individual's rating on each domain by its relative importance. The domains that might have been important for one's QOL before may not be as important on a subsequent occasion. If one chooses different domains on a subsequent occasion from those chosen previously, it could be actually argued that he/she has re-conceptualized what QOL means to him/her. But if he/she was allowed to select as many cues as he/she 
Response shift effect (RPT) on Global QL

\begin{tabular}{lcc}
\multicolumn{1}{c}{ Studyname } & & \\
& $\begin{array}{c}\text { Hedges's } \\
\text { g }\end{array}$ & $\begin{array}{c}\text { Standard } \\
\text { error }\end{array}$ \\
Schwartz(1999) & 0.589 & 0.315 \\
Jansen (2000) & 0.595 & 0.218 \\
Bernhard (2001) & 0.297 & 0.124 \\
Ree (2005) & 0.822 & 0.202 \\
Korfage (2007) & 0.427 & 0.200 \\
& 0.471 & 0.083
\end{tabular}

\begin{tabular}{rrr}
\multicolumn{3}{c}{ Statistics for eachstudy } \\
\hline Variance & $\begin{array}{r}\text { Lower } \\
\text { limit }\end{array}$ & $\begin{array}{c}\text { Upper } \\
\text { limit }\end{array}$ \\
0.099 & -0.028 & 1.206 \\
0.048 & 0.168 & 1.022 \\
0.015 & 0.054 & 0.540 \\
0.041 & 0.426 & 1.218 \\
0.040 & 0.035 & 0.819 \\
0.007 & 0.308 & 0.633
\end{tabular}

$\begin{array}{rr} & \\ \text { Z-Value } & \text { p-Value } \\ 1.870 & 0.062 \\ 2.729 & 0.006 \\ 2.395 & 0.017 \\ 4.069 & 0.000 \\ 2.135 & 0.033 \\ 5.683 & 0.000\end{array}$

\begin{tabular}{cc|}
\multicolumn{2}{c}{ Samplesize } \\
Pretest & Thentest \\
21 & 21 \\
44 & 44 \\
132 & 132 \\
53 & 53 \\
51 & 51
\end{tabular}

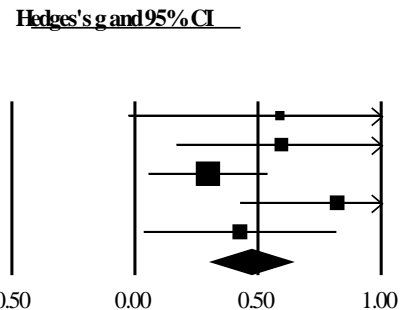

$-0.50$

0.00

1.00

Figure 2. Summary estimates of effect size of each study and overall weighted mean ESs and CI on recalibration effect of global QL assessment Square indicate point the estimates of individual studies, and bars indicate their 95\% CIs. Diamonds indicates the ESs and 95\% CIs pooling across studies recruited. Sample sizes were based on usable data extracted for metaanalysis; therefore, it may be underestimated smaller than the number reported in original studies.

Response shift effect (RPT) on Fatigue

\begin{tabular}{|c|c|c|c|}
\hline \multicolumn{2}{|c|}{ Studyneme } & \multirow[b]{2}{*}{$\begin{array}{c}\text { Hedges's } \\
\text { g }\end{array}$} & \multirow[b]{2}{*}{$\begin{array}{c}\text { Standard } \\
\text { error }\end{array}$} \\
\hline & & & \\
\hline Spranger & (1996) & -0.797 & \\
\hline Spranger & (1999) & -0.239 & \\
\hline Visser & (2000) & -0.127 & \\
\hline Jansen & (2000) & -0.127 & \\
\hline Visser & (2005) & -0.050 & \\
\hline Andrylow: & i (2008) & -0.465 & \\
\hline
\end{tabular}

\begin{tabular}{rrr}
\multicolumn{3}{c}{ Satisticsfor eachstudy } \\
\hline & $\begin{array}{r}\text { Lower } \\
\text { Variance }\end{array}$ & $\begin{array}{r}\text { Upper } \\
\text { limit } \\
\text { limit }\end{array}$ \\
0.083 & -1.361 & -0.233 \\
0.029 & -0.572 & 0.094 \\
0.010 & -0.323 & 0.069 \\
0.045 & -0.544 & 0.290 \\
0.012 & -0.264 & 0.164 \\
0.018 & -0.726 & -0.204 \\
0.003 & -0.318 & -0.095
\end{tabular}

\begin{tabular}{cccc} 
& & \multicolumn{2}{c}{ Samplesine } \\
Z-Value & p-Vahre & Pretest & Thentest \\
-2767 & 0.006 & 26 & 26 \\
-1.406 & 0.160 & 70 & 70 \\
-1.270 & 0.204 & 199 & 199 \\
-0.596 & 0.551 & 44 & 44 \\
-0.459 & 0.646 & 168 & 168 \\
-3.496 & 0.000 & 116 & 116 \\
-3631 & 0.00 & &
\end{tabular}
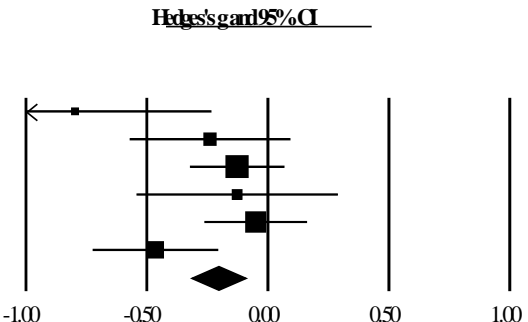

Figure 3. Summary estimates of effect size of each study and overall weighted mean ESs and CI on recalibration effect of Fatigue assessment Square indicate point the estimates of individual studies, and bars indicate their 95\% CIs. Diamonds indicates the ESs and 95\% CIs pooling across studies recruited. Sample sizes were based on usable data extracted for metaanalysis; therefore, it may be underestimated smaller than the number reported in original studies.

Table 3. Overall response shift effect on quality of life assessing.

\begin{tabular}{cccccc}
\hline & $\mathrm{d}^{+}$ & z value & $95 \%$ CI & df & Qt \\
\hline GQL & 0.47 & 5.68 & $0.308-0.633$ & 4 & $5.499(p=0.24)$ \\
FT & -0.207 & 3.629 & $-0.318--0.095$ & 5 & $10.858(p=0.054)$ \\
\hline
\end{tabular}

wished and he/she included all of the domains previously chosen as well as any new ones, then this would be more likely to indicate reprioritisation rather than reconceptualization.

\section{Discussion}

The assessment of quality of life over time on self-reported questionnaires may be affected by the occurrence of RS. The response shift effect may conceal the "real" effects of a specific event like training, treatment, or programme over time in the outcome of research [48]. We performed a systematic review to evaluate comprehensively the effect of response shift occurrence on the QOL of cancer patients. Among the studies included in this review, change in self-reported QOL was assessed between two time points for evidence of recalibration, reprioritization and reconceptualization of RS. All three types of RS were analyzed using either a research-design technique or statistical modeling. The then-test, a research-design method, represents a theory-driven withinsubject test of change [51]. The statistical model SEM offers an assessment of group level effects over time, which proves the fit of observed data to a hypothesized model of statistical changes.

The then-test is relatively straightforward to create and analyze [41]. The retrospective reassessment (RPT) was the most common method used in this review (10/14, 71.4\%) to recognize the recalibration response shift. Of the 5 studies which provided adequate data to examine the effect size of RS on GQL, the pooled estimate appeared to show a moderate shift. Similarly, analyses of the fatigue subscale of QOL from six studies indicated a small effect of RS in the cancer patient-reported outcome. It indicated that cancer patients' internal standard 
for assessing their level of QOL is not stable.

However, lacking the evidence from a control group reduces the credibility of the conclusion. Finding a comparable study group can heighten the validity of the then-test approach, but it is a challenge to explore the issue. Among the studies reviewed, only one study [51] used randomized allocation to treatment regimens to compare the impact of RS on the assessment of treatment effects in a clinical trial. But not surprisingly, because treatments may still result in different levels and types of influence to which subjects attempt to adjust [10], this RCT did not solve the control issue of RS comparison [51].

Even if one chooses a healthy population-base control group, it is still problematic because they have no reliable point of reference or anchor for going back to then. Since cancer patients face a life-threatening illness, they may experience changes through varied tough treatments. One study [48] therefore included a healthy control group only in the comparison of baseline data instead of follow-up events. Conversely, another study [53] successfully identified that the partners of prostate cancer participants could be a comparison group. The caregivers of those patients would be an appropriate control group because they remember the period when their loved one was diagnosed with cancer, and hence had a relevant point of reference. Furthermore, as with the study conducted by Jansen et al. [50], one can add several control items in the then-test to compare the evidence where RS might be absent on those items.

The other disadvantages of the then-test are that they are time-consuming and they impose burdens on participants due to the need to reassess the previous status at post-test. To minimize participant burden of the then-test, some researchers would select best domains/items where scale recalibration can be expected to happen [41] [48] instead of completing whole questionnaire items. Based on this strategy, there were 5 projects [48] [50] [51] [54] [55] that used representative items in the RPT. It is for this reason that the dimensions of fatigue and overall QOL were used frequently in the studies reviewed.

With regard to the instrument for RS measure, QOL measures currently used in clinical research and in this review were not designed to account for response shifts, but one [59] used the SEIQOL-DW. Its results demonstrated that neither reconceptualization nor reprioritization occurred. This might be a true finding; however, we need to consider other matters when interpreting these results. The sample size was small. Moreover, although the tool had good properties, the participants reported that it was not easy to nominate five areas which were important to their QOL. The challenge of the SEIQOL-DW utility was also represented in other studies [43] [62] [63].

The non-significant difference on the reconceptualization and reprioritization RS identified was consistent with that of Oort's [58] under the SEM method. Despite the fact that using a statistical approach has the advantage that there is no requirement for the administration of additional measures, reaching an appropriate subjectto-variable ratio using this method needs relatively large sample sizes which may limit its feasibility.

While the present review has some overlap with the meta-analysis conducted by Schwartz et al. [18] [64], we used a different methodology to focus on the QOL outcome in specific study populations.

There are several inherent limitations in this review. A noteworthy feature of studies included in this review was the wide variability in the methods and measures used. This variation precluded pooling studies and to make overall conclusions regarding the impact of RS. A further limitation was the low number of eligible studies and the fact that some of them lacked sufficient statistical information to calculate the effect size. We attempted to rectify these limitations in the following ways.

First of all, we circumscribed our inspection of quantitative studies to avoid heterogeneity of study design. In addition, in those longitudinal studies using varied instruments the common domains were analyzed, and we inferred the trend to ascertain the result for the effect of RS. The direction of RS was not discussed, we only focus on the magnitude of RS detecting. Albeit homogeneity statistics elicited among those papers, we derived more credit from the visual inspection of the forest plot. We found that the funnel plots for GQL and FT were quite symmetrical, indicating the likely absence of publication bias amongst those articles. To extend the papers' usability to deduce effect size, we attempted to extract data comprehensively from the studies reviewed. One study [53] did not report sufficient statistical information (lack of means and standard deviation), but reported the exact $p$; hence the effect size was estimated using conversion formula [65]. Two studies [46] [48] claimed that the pretest/then-test comparison changed significantly, but provided no exact information for the ES calculation. We employed a conservative way to estimate it by computing the effect size using a $p$-value of 0.05 with the corresponding degree of freedom. Due to the fact that the pooled effect size obtained was underestimated, the result should be more convincing. 
One project [48] demonstrated non-significant RS over one week of follow-up, but a moderate effect $(d=0.6)$ was observed at 3-month follow-up. The evidence probably indicated that the adaptation response would appear over a longer illness period instead of a short (e.g., one week) period. But as we know no study can prove how much time is needed to generate this psychological phenomenon.

The focus of this review limits the conclusions to be applicable only to cancer patients. It may also be limited to the Caucasians because of the places where the studies had been conducted. Therefore, we strongly recommend that this study be repeated or conducted with different ethnic and cultural groups, and designed to vary the time period to be compared.

\section{Conclusion}

Cancer patients may have a concomitant impact when experiencing the change of health and ineluctable treatments. Theoretically, for studies exploring health, fatigue, or attitude, response shifts may occur when a study is designed to evaluate changes of patient-report outcomes repeatedly using a retrospective pretest method which enabled researchers to detect the presence, magnitude, and direction of recalibration. Incorporating this theoretical concept into the methodology of assessment may optimize the practical implication.

\section{Relevance to Clinical Practice}

Healthcare providers should be alert to response shift contributing to evaluate the efficacy of clinical intervention. A regular subjective cancer patients QOL measurement approach, will need to control for the attribute of situational adaptation. Additional procedures could be taken to collect and integrate other objective measures along with longitudinal follow-up data, will provide more complete and sensitive assessments of change. Patients' adaptation to the disease can then be more precisely acquired.

\section{References}

[1] Herber, O.R., Schnepp, W. and Rieger, M.A. (2007) A Systematic Review on the Impact of Leg Ulceration on Patients' Quality of Life. Health and Quality of Life Outcomes, 5, 1-12.

[2] Fortin, M., Lapointe, L., Hudon, C., et al. (2004) Multimorbidity and Quality of Life in Primary Care: A Systematic Review. Health and Quality of Life Outcomes, 2, 1-12.

[3] Berger, A.M., Sankaranarayanan, J. and Watanabe-Galloway, S. (2007) Current Methodological Approaches to the Study of Sleep Disturbances and Quality of Life in Adults with Cancer: A Systematic Review. Psycho Oncology, 16, 401-420. http://dx.doi.org/10.1002/pon.1079

[4] Wiklund, I. (2004) Assessment of Patient-Reported Outcomes in Clinical Trials: The Example of Health-Related Quality of Life. Fundamental and Clinical Pharmacology, 18, 351-363. http://dx.doi.org/10.1111/j.1472-8206.2004.00234.x

[5] Shimozuma, K., Imai, H., Kuroi, K., et al. (2007) Recent Topics of Health Outcomes Research in Oncology. Breast Cancer, 14, 60-65. http://dx.doi.org/10.2325/jbcs.14.60

[6] Chao, L.F., Zhang, A.L., Liu, H.E., et al. (2009) The Efficacy of Acupoint Stimulation for the Management of TherapyRelated Adverse Events in Patients with Breast Cancer: A Systematic Review. Breast Cancer Research and Treatment, 118, 255-267. http://dx.doi.org/10.1007/s10549-009-0533-8

[7] Johnson, J.R. and Temple, R. (1985) Food and Drug Administration Requirements for Approval of New Anticancer Drugs. Cancer Treatment Reports, 69, 1155-1159.

[8] Patrick, D.L., Burke, L.B., Powers, J.H., et al. (2007) Patient-Reported Outcomes to Support Medical Product Labeling Claims: FDA Perspective. Value in Health, 10, 125-137. http://dx.doi.org/10.1111/j.1524-4733.2007.00275.x

[9] Med, B. (2006) Guidance for Industry: Patient-Reported Outcome Measures: Use in Medical Product Development to Support Labeling Claims: Draft Guidance. Health and Quality of Life Outcomes, 4, 79-99. http://dx.doi.org/10.1186/1477-7525-4-79

[10] Sprangers, M.A. and Schwartz, C.E. (1999) Integrating Response Shift into Health-Related Quality of Life Research: A Theoretical Model. Social Science \& Medicine, 48, 1507-1515. http://dx.doi.org/10.1016/S0277-9536(99)00045-3

[11] Sprangers, M.A.G., Moinpour, C.M., Moynihan, T.J., Patrick, D.L. and Revicki, D.A., Clinical Significance Consensus Meeting Group (2002) Assessing Meaningful Change in Quality of Life over Time: A Users' Guide for Clinicians. Mayo Clinic Proceedings, 77, 561-571.

[12] Sprangers, M.A. and Schwartz, C.E. (1999) Integrating Response Shift into Health-Related Quality of Life Research: 
A Theoretical Model. Social Science \& Medicine, 48, 1507-1515. http://dx.doi.org/10.1016/S0277-9536(99)00045-3

[13] Oort, F.J. (2005) Using Structural Equation Modeling to Detect Response Shifts and True Change. Quality of Life Research, 14, 587-598. http://dx.doi.org/10.1007/s11136-004-0830-y

[14] Korfage, I.J., de Koning, H.J., Habbema, J.D., Schröder, F.H. and Essink-Bot, M.L. (2007) Side-Effects of Treatment for Localized Prostate Cancer: Are They Valued Differently by Patients and Healthy Controls? BJU International, 99, 801-806. http://dx.doi.org/10.1111/j.1464-410X.2006.06707.x

[15] Utne, I., Miaskowski, C., Bjordal, K., Paul, S.M., Jakobsen, G. and Rustøen, T. (2008) The Relationship between Hope and Pain in a Sample of Hospitalized Oncology Patients. Palliative and Supportive Care, 6, 327-334. http://dx.doi.org/10.1017/S1478951508000527

[16] Hickok, J.T., Morrow, G.R., McDonald, S. and Bellg, A.J. (1996) Frequency and Correlates of Fatigue in Lung Cancer Patients Receiving Radiation Therapy: Implications for Management. Journal of Pain and Symptom Management, 11, 370-377. http://dx.doi.org/10.1016/0885-3924(96)00008-5

[17] Barclay-Goddard, R., Epstein, J.D. and Mayo, N.E. (2009) Response Shift: A Brief Overview and Proposed Research Priorities. Quality of Life Research, 18, 335-346. http://dx.doi.org/10.1007/s11136-009-9450-x

[18] Schwartz, C.E., Bode, R., Repucci, N., Becker, J., Sprangers, M.A.G. and Fayers, P.M. (2006) The Clinical Significance of Adaptation to Changing Health: A Meta-Analysis of Response Shift. Quality of Life Research, 15, 1533-1550. http://dx.doi.org/10.1007/s11136-006-0025-9

[19] Moher, D., Cook, D.J., Eastwood, S., Olkin, I., Rennie, D. and Stroup, D.F. (1999) Improving the Quality of Reports of Meta-Analyses of Randomised Controlled Trials: The QUOROM Statement. Lancet, 354, 1896-1900. http://dx.doi.org/10.1016/S0140-6736(99)04149-5

[20] Rietman, J.S., Dijkstra, P.U., Hoekstra, H.J., Eisma, W.H., Szabo, B.G., Groothoff, J.W. and Geertzen, J.H.B. (2003) Late Morbidity after Treatment of Breast Cancer in Relation to Daily Activities and Quality of Life: A Systematic Review. European Journal of Surgical Oncology, 29, 229-238. http://dx.doi.org/10.1053/ejso.2002.1403

[21] Viera, A.J. and Garrett, J.M. (2005) Understanding Interobserver Agreement: The Kappa Statistic. Family Medicine, 37, 360-363.

[22] Chen, S.M., Liu, M.F., Cook, J., Bass, S. and Lo, S.K. (2009) Sedentary Lifestyle as a Risk Factor for Low Back Pain: A Systematic Review. International Archives of Occupational and Environmental Health, 82, 797-806. http://dx.doi.org/10.1007/s00420-009-0410-0

[23] Lipsey, M.W. and Wilson, D.B. (2001) Practical Meta-Analysis. Sage Publications, Inc., Thousand Oaks.

[24] Borenstein, M. and Rothstein, H. (1999) Comprehensive Meta-Analysis: A Computer Program for Research Synthesis. Version 1.0. 23 [Computer Software], Biostat, Englewood Cliffs.

[25] Egger, M., Smith, G.D., Schneider, M. and Minder, C. (1997) Bias in Meta-Analysis Detected by a Simple, Graphical Test. British Medical Journal, 315, 629. http://dx.doi.org/10.1136/bmj.315.7109.629

[26] Cohen, J. (1988) Statistical Power Analysis for the Behavioral Sciences. Erlbaum Associates, Hillsdale.

[27] Sprangers, M.A. and Schwartz, C.E. (1999) The Challenge of Response Shift for Quality-of-Life-Based Clinical Oncology Research. Annals of Oncology, 10, 747-749. http://dx.doi.org/10.1023/A:1008305523548

[28] Wilson, B. (1999) Clinical Understanding and Clinical Implications of Response Shift. Social Science \& Medicine, 48, 1577-1588. http://dx.doi.org/10.1016/S0277-9536(99)00050-7

[29] Sprangers, M. (2002) Quality-of-Life Assessment in Oncology. Acta Oncologica, 41, 229-237. http://dx.doi.org/10.1080/02841860260088764

[30] Lowy, A. and Bernhard, J. (2004) Quantitative Assessment of Changes in Patients' Constructs of Quality of Life: An Application of Multilevel Models. Quality of Life Research, 13, 1177-1185. http://dx.doi.org/10.1023/B:QURE.0000037510.17893.d2

[31] Chow, E., Chiu, H., Doyle, M., Hruby, G., Holden, L., Barnes, E.A., Tsao, M., Mallia, G., Harris, K. and Danjoux, C. (2007) Patient Expectation of the Partial Response and Response Shift in Pain Score. Supportive Cancer Therapy, 4, 110-118. http://dx.doi.org/10.3816/SCT.2007.n.005

[32] Cella, D., Hahn, E.A. and Dineen, K. (2002) Meaningful Change in Cancer-Specific Quality of Life Scores: Differences between Improvement and Worsening. Quality of Life Research, 11, 207-221. http://dx.doi.org/10.1023/A:1015276414526

[33] Thompson-Fawcett, M.W., Richard, C.S., O’Connor, B.I., Cohen, Z. and McLeod, R.S. (2000) Quality of Life Is Excellent after a Pelvic Pouch for Colitis-Associated Neoplasia. Diseases of the Colon \& Rectum, 43, 1497-1502. http://dx.doi.org/10.1007/BF02236727

[34] Roos, E.J., De Graeff, A., Van Eijkeren, M.A., Boon, T.A. and Heintz, A.P.M. (2004) Quality of Life after Pelvic Exenteration. Gynecologic Oncology, 93, 610-614. http://dx.doi.org/10.1016/j.ygyno.2004.03.008 
[35] Schwartz, C.E. and Sendor, R.M. (1999) Helping Others Helps Oneself: Response Shift Effects in Peer Support. Social Science \& Medicine, 48, 1563-1575. http://dx.doi.org/10.1016/S0277-9536(99)00049-0

[36] Mayo, N.E., Scott, S.C., Dendukuri, N., Ahmed, S. and Wood-Dauphinee, S. (2008) Identifying Response Shift Statistically at the Individual Level. Quality of Life Research, 17, 627-639. http://dx.doi.org/10.1007/s11136-008-9329-2

[37] Sharpley, C.F. and Christie, D.R.H. (2006) How I Was Then and How I Am Now: Current and Retrospective SelfReports of Anxiety and Depression in Australian Women with Breast Cancer. Psycho-Oncology, 16, 752-762. http://dx.doi.org/10.1002/pon.1125

[38] Jorngarden, A., Mattsson, E. and von Essen, L. (2007) Health-Related Quality of Life, Anxiety and Depression among Adolescents and Young Adults with Cancer: A Prospective Longitudinal Study. European Journal of Cancer, 43, 1952-1958. http://dx.doi.org/10.1016/j.ejca.2007.05.031

[39] Westerman, M.J., Hak, T., Echteld, M.A., Groen, H.J.M. and van der Wal, G. (2007) Change in What Matters to Palliative Patients: Eliciting Information about Adaptation with SEIQoL-DW. Palliative Medicine, 21, 581-586. http://dx.doi.org/10.1177/0269216307081938

[40] Kidd, P., Parshall, M., Wojcik, S. and Struttmann, T. (2004) Assessing Recalibration as a Response-Shift Phenomenon. Nursing Research, 53, 130-135. http://dx.doi.org/10.1097/00006199-200403000-00009

[41] Schwartz, C.E., Sprangers, M.A.G., Carey, A. and Reed, G. (2004) Exploring Response Shift in Longitudinal Data. Psychology \& Health, 19, 51-69. http://dx.doi.org/10.1080/0887044031000118456

[42] Brossart, D., Clay, D. and Willson, V. (2002) Methodological and Statistical Considerations for Threats to Internal Validity in Pediatric Outcome Data: Response Shift in Self-Report Outcomes. Journal of Pediatric Psychology, 27, 97-107. http://dx.doi.org/10.1093/jpepsy/27.1.97

[43] Ring, L., Höfer, S., Heuston, F., Harris, D. and O’Boyle, C. (2005) Response Shift Masks the Treatment Impact on Patient Reported Outcomes (PROs): The Example of Individual Quality of Life in Edentulous Patients. Health and Quality of Life Outcomes, 3, 55.

[44] Schwartz, C., Merriman, M., Reed, G. and Hammes, B.J. (2004) Measuring Patient Treatment Preferences in Endof-Life Care Research: Applications for Advance Care Planning Interventions and Response Shift Research. Journal of Palliative Medicine, 7, 233-245. http://dx.doi.org/10.1089/109662104773709350

[45] Ahmed, S., Mayo, N., Wood-Dauphinee, S., Hanley, J.A. and Robin Cohen, S. (2004) Response Shift Influenced Estimates of Change in Health-Related Quality of Life Poststroke. Journal of Clinical Epidemiology, 57, 561-570. http://dx.doi.org/10.1016/j.jclinepi.2003.11.003

[46] Sprangers, M.A.G. (1996) Response-Shift Bias: A Challenge to the Assessment of Patients' Quality of Life in Cancer Clinical Trials. Cancer Treatment Reviews, 22, 55-62.

[47] Sprangers, M.A.G., Van Dam, F.S.A.M., Broersen, J., Lodder, L., Wever, L., Visser, M.R.M., Oosterveld, P. and Smets, E.M.A. (1999) Revealing Response Shift in Longitudinal Research on Fatigue: The Use of the Thentest Approach. Acta Oncologica, 38, 709-718. http://dx.doi.org/10.1080/028418699432860

[48] Schwartz, C.E., Feinberg, R.G., Jilinskaia, E. and Applegate, J.C. (1999) An Evaluation of a Psychosocial Intervention for Survivors of Childhood Cancer: Paradoxical Effects of Response Shift over Time. Psycho-Oncology, 8, 344-354. http://dx.doi.org/10.1002/(SICI)1099-1611(199907/08)8:4<344::AID-PON399>3.0.CO;2-T

[49] Visser, M., Smets, E., Sprangers, M. and de Haes, H.J.C.J.M. (2000) How Response Shift May Affect the Measurement of Change in Fatigue. Journal of Pain and Symptom Management, 20, 12-18. http://dx.doi.org/10.1016/S0885-3924(00)00148-2

[50] Jansen, S., Stiggelbout, A., Nooij, M., Noordijk, E.M. and Kievit, J. (2000) Response Shift in Quality of Life Measurement in Early-Stage Breast Cancer Patients Undergoing Radiotherapy. Quality of Life Research, 9, 603-615. http://dx.doi.org/10.1023/A:1008928617014

[51] Bernhard, J., Lowy, A., Maibach, R. and Hürny, C. (2001) Response Shift in the Perception of Health for Utility Evaluation. An Explorative Investigation. European Journal of Cancer, 37, 1729-1735. http://dx.doi.org/10.1016/S0959-8049(01)00196-4

[52] Visser, M.R., Oort, F.J. and Sprangers, M.A. (2005) Methods to Detect Response Shift in Quality of Life Data: A Convergent Validity Study. Quality of Life Research, 14, 629-639. http://dx.doi.org/10.1007/s11136-004-2577-x

[53] Rees, J., Clarke, M., Waldron, D., O’Boyle, C., Ewings, P. and MacDonagh, R.P. (2005) The Measurement of Response Shift in Patients with Advanced Prostate Cancer and Their Partners. Health and Quality of Life Outcomes, 3, 21.

[54] Korfage, I., de Koning, H. and Essink-Bot, M. (2007) Response Shift Due to Diagnosis and Primary Treatment of Localized Prostate Cancer: A Then-Test and a Vignette Study. Quality of Life Research, 16, 1627-1634. http://dx.doi.org/10.1007/s11136-007-9265-6 
[55] Andrykowski, M.A., Donovan, K.A. and Jacobsen, P.B. (2009) Magnitude and Correlates of Response Shift in Fatigue Ratings in Women Undergoing Adjuvant Therapy for Breast Cancer. Journal of Pain and Symptom Management, 37, 341-351. http://dx.doi.org/10.1016/j.jpainsymman.2008.03.015

[56] Lepore, S.J. and Eton, D.T. (2000) Response Shifts in Prostate Cancer Patients: An Evaluation of Suppressor and Buffer Models. In: Adaptation to Changing Health: Response Shift in Quality-of-Life Research, Washington DC, 37-51.

[57] Hagedoorn, M., Sneeuw, K. and Aaronson, N. (2002) Changes in Physical Functioning and Quality of Life in Patients with Cancer: Response Shift and Relative Evaluation of One's Condition. Journal of Clinical Epidemiology, 55, 176183. http://dx.doi.org/10.1016/S0895-4356(01)00438-3

[58] Oort, F.J., Visser, M.R.M. and Sprangers, M.A.G. (2005) An Application of Structural Equation Modeling to Detect Response Shifts and True Change in Quality of Life Data from Cancer Patients Undergoing Invasive Surgery. Quality of Life Research, 14, 599-609. http://dx.doi.org/10.1007/s11136-004-0831-x

[59] Sharpe, L., Butow, P., Smith, C., McConnell, D. and Clarke, S. (2005) Changes in Quality of Life in Patients with Advanced Cancer: Evidence of Response Shift and Response Restriction. Journal of Psychosomatic Research, 58, 497504. http://dx.doi.org/10.1016/j.jpsychores.2005.02.017

[60] Hedges, L.V. and Olkin, I. (1985) Statistical Methods for Meta-Analysis. Academic Press, New York.

[61] Moons, P., Marquet, K., Budts, W. and De Geest, S. (2004) Validity, Reliability and Responsiveness of the "Schedule for the Evaluation of Individual Quality of Life-Direct Weighting” (SEIQoL-DW) in Congenital Heart Disease. Health and Quality of Life Outcomes, 2, 27. http://dx.doi.org/10.1186/1477-7525-2-27

[62] Campbell, S. and Whyte, F. (1999) The Quality of Life of Cancer Patients Participating in Phase I Clinical Trials Using SEIQoL-DW. Journal of Advanced Nursing, 30, 335-343. http://dx.doi.org/10.1046/j.1365-2648.1999.01079.x

[63] Neudert, C., Wasner, M. and Borasio, G.D. (2001) Patients’ Assessment of Quality of Life Instruments: A Randomised Study of SIP, SF-36 and SEIQoL-DW in Patients with Amyotrophic Lateral Sclerosis. Journal of the Neurological Sciences, 191, 103-109. http://dx.doi.org/10.1016/S0022-510X(01)00612-8

[64] Schwartz, C.E., Bode, R., Repucci, N., Becker, J., Sprangers, M.A. and Fayers, P.M. (2006) The Clinical Significance of Adaptation to Changing Health: A Meta-Analysis of Response Shift. Quality of Life Research, 15, 1533-1550. http://dx.doi.org/10.1007/s11136-006-0025-9

[65] Rosenthal, R. (1991) Meta-Analytic Procedures for Social Research. Sage Publications, Inc., Thousand Oaks. http://dx.doi.org/10.4135/9781412984997 